\title{
Digital Curation for Cultural and Intellectual Assets: A Taiwan Perspective
}

\author{
Hao-Ren Ke \\ Graduate Institute of Library and Information Studies, \\ National Taiwan Normal University, Taiwan, R.O.C. \\ clavenke@ntnu.edu.tw \\ Shu-Hsien Tseng \\ National Central Library, Taiwan, R.O.C. \\ egret.tseng@gmail.com
}

\begin{abstract}
This paper describes the efforts of the National Central Library, Taiwan, in its International Digitalization Project of Rare Books and Domestic Digitization Project of Modern Chinese Books. The former project is a collaboration with the U.S. Library of Congress, University of Washington, University of California, Berkeley, University of Toronto, and the Bibliothèque nationale de France to digitize Chinese rare books. The latter project is a collaboration with the National Taiwan University Library, National Taiwan Normal University Library, National ChengChi University Libraries, National Taiwan Library, National Library of Public Information, together with other public libraries, cultural institutions, and government agencies to digitalize books published in the twentieth century, especially during the period 1911-1949.
\end{abstract}

\section{INTRODUCTION}

Digital information on the Internet is massively increasing and having significant impacts on people in many areas, such as education, recreation, research and culture. The generated digital information is not as safe and eternal as people may think. The long term survival of digital information is at risk because of many factors such as technology obsolescence and technology fragility (Harvey, 2010); therefore, it is essential to preserve, manage and use digital information.

Digital curation can be defined broadly as the appraisal, digitization, management, preservation and use of, as well as value addition to digital assets for short-term and long-term use (Wikipedia 2016a). According to the Digital Curation Centre (DCC), “digital curation involves maintaining, preserving and adding value to digital research data throughout its lifecycle” (Digital Curation Centre, 2008). The range of digital research data is quite broad, including government information, scientific data, and cultural and intellectual assets.

Over the past two decades, due to the rapid development of information and communication technologies, there has been a rapid growth of digitization projects around the world aiming at preserving important cultural and intellectual assets. Through digitization and dissemination over the Internet, cultural and intellectual assets can be more readily available to the public. 
Table 1. Partners in the International Digitalization Project of Rare Books

\begin{tabular}{llrr}
\hline Project Period & Partner & Titles & Images \\
& & & \\
\hline $2005-2012$ & Library of Congress, USA & 2,025 & $1,032,401$ \\
$2010-2013$ & University of Washington & 382 & 226,432 \\
$2011-2013$ & University of California, Berkeley & 306 & 214,452 \\
2014 & University of Toronto & 219 & 298,815 \\
2015 & Bibliothèque nationale de France & 294 & 80,000 \\
Total & & 3,226 & $1,852,100$ \\
\hline
\end{tabular}

This article shares the experience of the National Central Library, Taiwan, in digital curation, specifically in two collaborative projects. The first project seeks international cooperation for digitizing Chinese rare books; the second project collaborates with government agencies and libraries in Taiwan for digitizing Chinese books published in the twentieth century, especially during the period of 1911-1949.

\section{INTERNATIONAL DIGITALIZATION PROJECT OF RARE BOOKS}

Since 2002, the Taiwan National Central Library (NCL) has been digitizing important collection resources as part of the government's National Digital Archives Program, which were later renamed Taiwan e-Learning and Digital Archives Program (n.d.). The types of digitized publications include rare books, local government documents, and periodicals and newspapers. Other digital content includes rubbings of stone inscriptions in Taiwan, news programs, genealogies and thesis papers (National Central Library, 2012).

As the national library of Taiwan, the NCL owns a rich and important collection of Chinese and Taiwanese documents. As many Chinese rare books are scattered around the world, it is desirable to collect these books together and provide a comprehensive online resource to support Chinese studies. To that end, the NCL initiated the International Digitalization Project of Rare Books in 2005 for digitizing Chinese rare books owned by overseas institutions. On the one hand, NCL can strengthen its digital Chinese collection through the collaborative digitization; on the other, the collaboration partners can produce quality digital archives of their Chinese rare books by leveraging NCL's rich experience in digitizing Chinese rare books.

NCL investigated the collections of many national libraries, academic libraries and cultural institutions around the world, and invited those which owned abundant and distinctive ancient Chinese books to participate in the project. The partner institutions include the U.S Library of Congress, the University of Washington, the University of California, Berkeley, the University of Toronto, and the Bibliothèque nationale de France. By 2015, 3,226 titles and a total of 1,852,100 images had been digitized. Table 1 lists the collaborative partners and the number of books digitized by each partner.

NCL started the collaboration with the Asian Division of the Library of Congress in 2005, and until 2012, the project had completed 2,025 titles, comprising 1,032,401 images. One representative rare book digitized in this project is the Gen Zhi Tu (耕織圖), which is a colored painting on silk paper by a Qing imperial painter in 1695 A.D. This book (see Figure 1), with detailed illustration and introduction on cultivation and weaving, can be regarded as one of the most vivid and valuable materials for research on Chinese agriculture. 


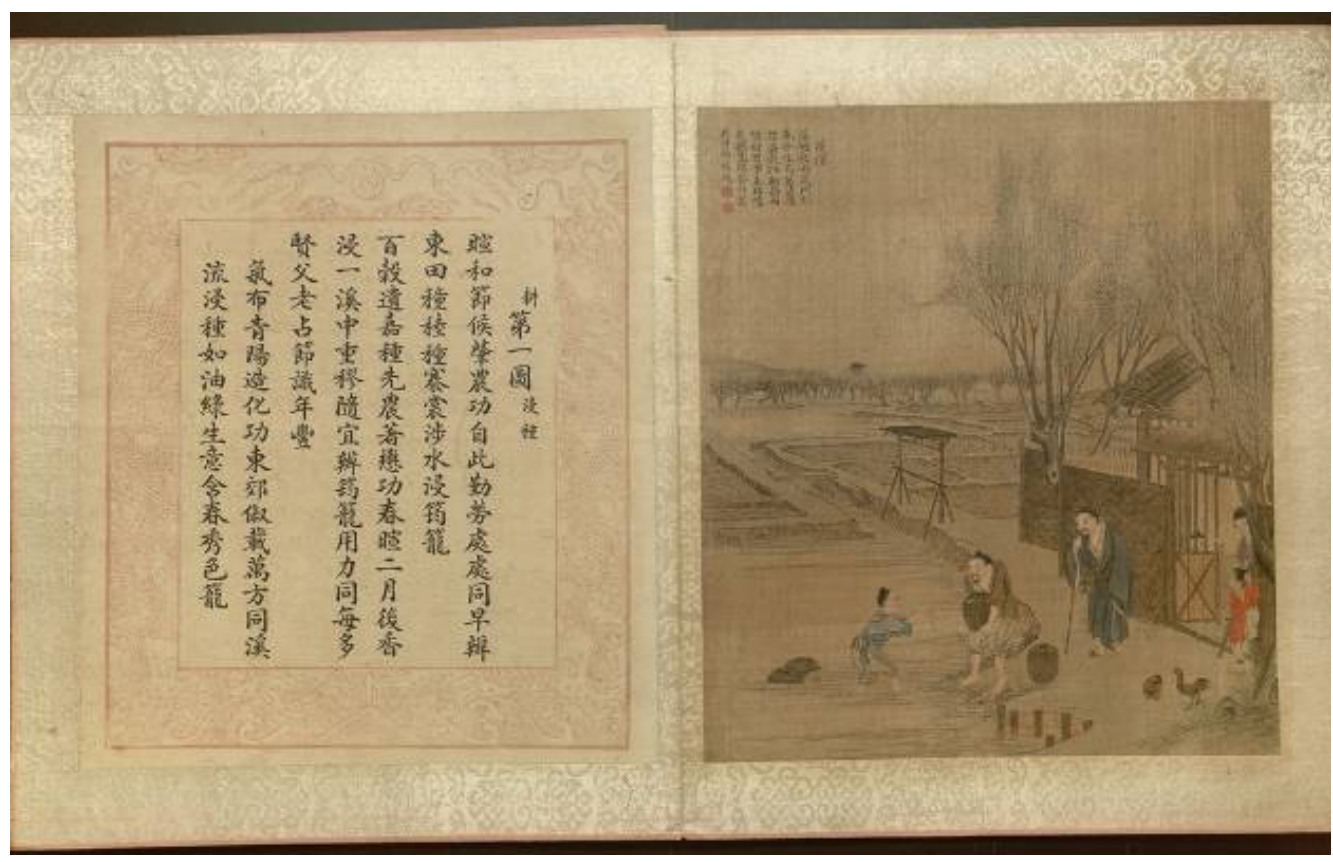

Figure 1. A page from Gen $\mathrm{Zhi} T \mathrm{Tu}$ (耕織圖)

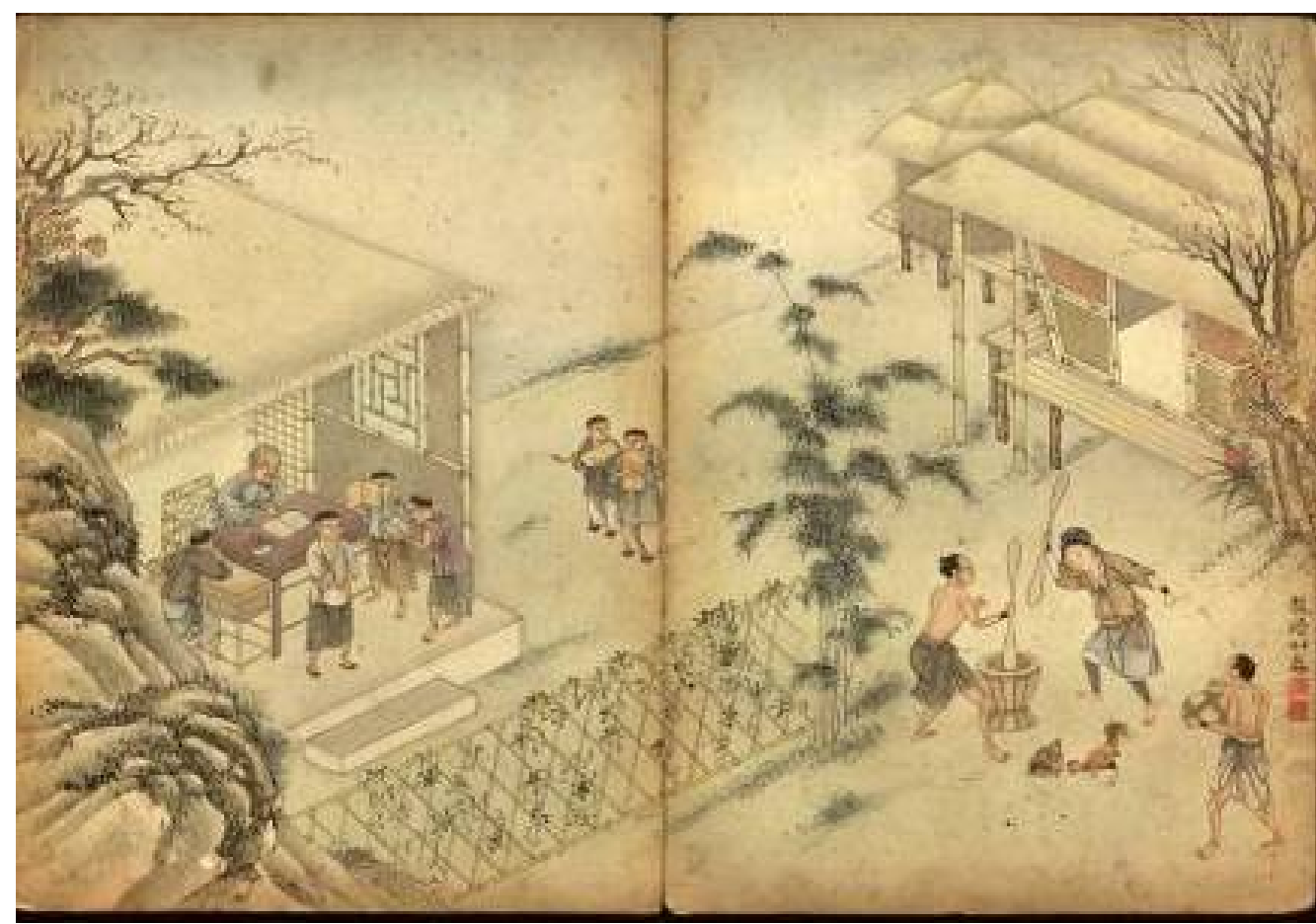

Figure 2. A page from Taiwan Aboriginal Villages (臺灣番社風俗)

Another valuable book from the Library Congress digitized in this project is Taiwan Aboriginal Villages (臺灣番社風俗). Emperor Qianlong ordered royal painters to portray this picture book when the Royal Inspector investigated Taiwan in 1744-1747 A.D (see Figure 2).

In January 2010, the NCL signed an agreement with the East Asian Library of the University of Washington, and sent a team over in July 2010. By 2013, the project had 
completed 382 titles, comprising 226,432 images. The rare book collection includes approximately 600 titles of Chinese rare books:

1. the rare books of Ming Dynasty (1368-1644)

2. editions of the Joseph F. Rock collection including many rare local gazetteers of Southwest China (西南地方志)

3. the Qian Qianyi (錢謙益) (a late Ming Dynasty poet-historian, 1582-1664) collection

4. the Hellmut Wilhelm collection (books from Professor Wilhelm, a former University of Washington faculty member and renowned sinologist).

In July 2011, the NCL and the C.V. Starr East Asian Library of the University of California, Berkeley, signed a collaboration agreement to digitize their Chinese rare books collection. By 2013, the project had completed 306 titles, comprising 214,452 images. The C.V. Starr East Asian Library holds several titles from the Ming Dynasty collector 劉承幹嘉 業堂's collection, and other important Sung, Yuan, Ming and early Ching Dynasty collections (altogether about 800 titles, comprising some 11,000 volumes).

Two recent collaboration partners are the University of Toronto and the Bibliothèque nationale de France. The East Asian Library of the University of Toronto owns a collection of rare materials acquired from China in the 1930's. Its special collection is now known as the $\mathrm{Mu}$ Collection. The agreement was signed in 2012, and the Digital Archive team at the In July 2011, the NCL and the C.V. Starr East Asian Library of the University of California, Berkeley, signed a collaboration agreement to digitize their Chinese rare books collection. By 2013, the project had completed 306 titles, comprising 214,452 images. The C.V. Starr East Asian Library holds several titles from the Ming Dynasty collector 劉承幹嘉業堂’ collection, and other important Sung, Yuan, Ming and early Ching Dynasty collections (altogether about 800 titles, comprising some 11,000 volumes). University started the digitization work in 2014. The project has completed the digitization of 219 rare books in Sung, Yuan, Ming Dynasties, with the result of 298,815 images.

In 2012, the NCL and the Bibliothèque nationale de France signed a memorandum of understanding to collaborate on personnel exchange and digital archiving. In 2014 and 2015, a staff member of the NCL was invited by the Bibliothèque's Profession Culture program to help catalog their ancient Chinese rare books. In August 2015, the two libraries signed an agreement to digitize titles selected by the NCL. The digitization achievement is 294 titles with 80,000 images, digitized by the Bibliothèque for NCL. In the abovementioned collaborations, the rare books to be digitized were chosen based on a two-phase strategy: nonoverlapping holdings were digitized in Phase 1; rare books that were different versions of the same titles were digitized in Phase 2. NCL followed the guideline developed by the National Digital Archives Program to standardize the digitization format. Specifically, the full-color (24-bit) scanning process produced 300dpi TIFF image files (for rare books) or 600dpi TIFF image files (for painting and calligraphy). TIFF files are used for long-term preservation and value-added applications. The TIFF files were converted into lower-resolution JPG files for preview and download. Quality control was conducted three times to ensure the digitization quality.

The digitized resources are described using metadata. Table 2 lists the metadata fields used in this project. At present, the NCL does not use any preservation metadata. 
Table 2 Metadata fields for Chinese rare books

\begin{tabular}{ll}
\hline Metadata field (in Chinese) & Metadata field (in English) \\
\hline 中名英譯 & Translation of Chinese names \\
資源類型 & Type of resource \\
藏品類型 & Type of holding \\
識別號 & Identification number \\
登錄號 & Accession No. \\
書號 & Book No. \\
題名 & Title \\
正題名 & Main title \\
其他題名 & Other title \\
拼音題名 & Roman title \\
責任者 & Person(s) of responsibility \\
名稱 & Name of person \\
技術種類 & Category \\
版本 & Edition \\
附註項 & Notes \\
數量 & Quantity \\
朝代或國別 & Name of dynasty or nationality \\
責任方式 & Mode of responsibility \\
其它貢獻者 & Other contributor(s) \\
出版資訊 & Publication data \\
責任者 & Publisher \\
現藏者 & Owner \\
地點 & Place of publication \\
年份 & Year of publication \\
\hline
\end{tabular}

To facilitate access to the Chinese rare books, the NCL developed a Rare Books \& Special Collections information system (http://rbook2.ncl.edu.tw/). This system is an integrated system for simultaneously searching many systems established by the NCL, including the Rare Book Digital Image Search System, the Union Catalog of Rare Books, the Taiwan Family Genealogy Union Catalogue, and the Bronze \& Stone \& Rubbing Database. It is worth noting that the Union Catalog of Rare Books system contains metadata records of Chinese rare books from almost 70 libraries around the world. The Rare Book Image Search System (http://rbook2.ncl.edu.tw/Search/Index/1) includes the product of the International Digitalization Project of Rare Books. Figure 3 shows the Rare Book Image Search System, and Figure 4 shows the metadata record for the rare book Taiwan Aboriginal Villages (臺灣 番社風俗). The book's images can be browsed on line by clicking the "Browse the Images" button. 


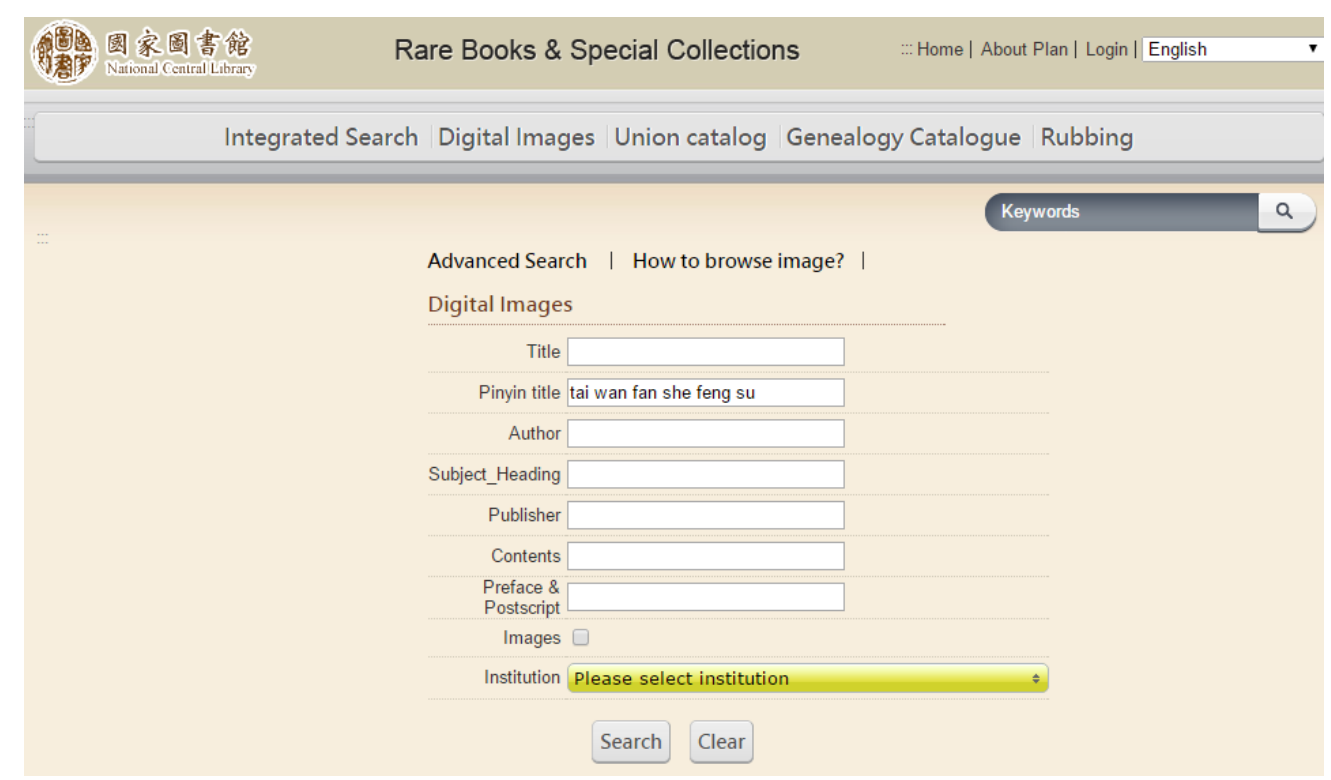

Figure 3. Rare book image search System (http://rbook2.ncl.edu.tw/Search/Index/1)

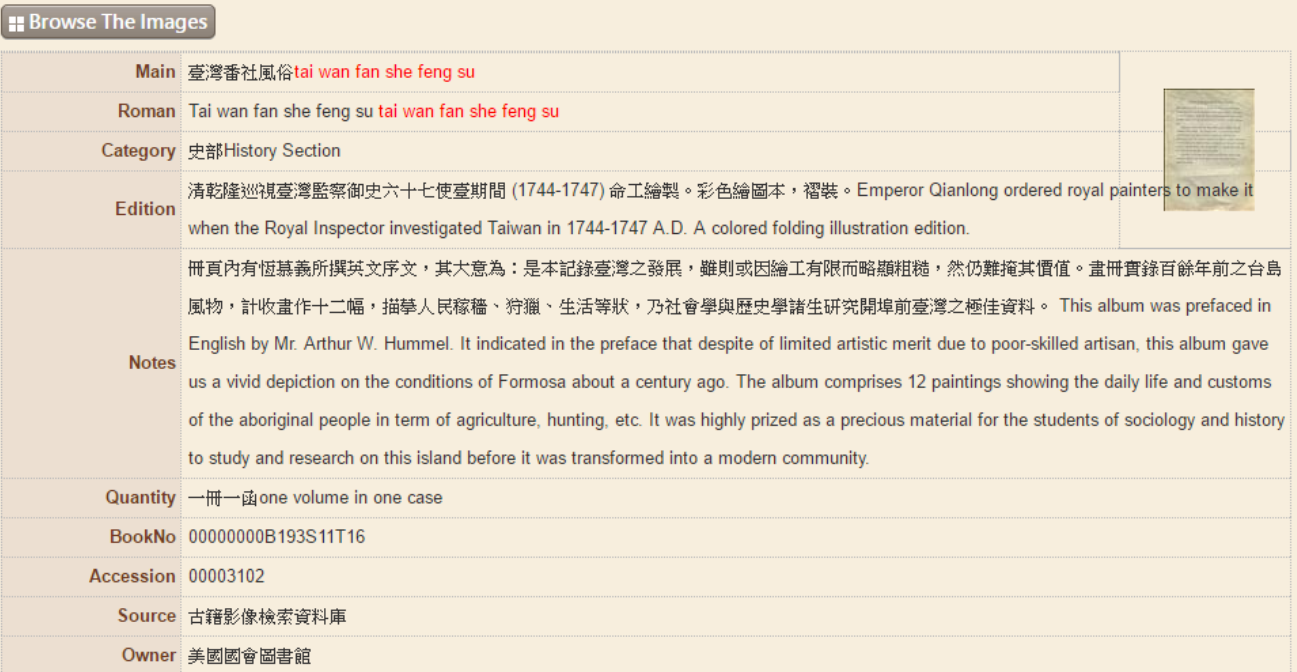

Figure 4. Metadata record for Taiwan Aboriginal Villages (臺灣番社風俗)

These efforts make collection materials more readily available to the public both in Taiwan and around the world. The library will continue to expand the scope of its digital collection and create new applications to continue improving digital archives for future generations.

Since 2008, the NCL has participated in the World Digital Library, a project of the U.S. Library of Congress with the support of the United Nations Educational, Scientific and Cultural Organization (UNESCO). As a founding member of the World Digital Library, the NCL continues to contribute digital images and metadata of its Chinese rare books and documents. The NCL selects those books and documents with interesting subject, vivid images and figures, and cultural value. Through participation in the World Digital Library, 
NCL's collection is made more readily available to the public both in Taiwan and around the world.

Value addition is important in digital duration. In view of the increasing worldwide interest in Chinese studies, the NCL formulated a plan to reprint and republish Chinese rare books. For example, in 2010, the NCL reprinted and republished the Diamond Sutra (金剛般 若波羅蜜經), originally published in 1341. In 2011, by permission of the Library of Congress, the NCL and a publisher published a children's book based on Taiwan Aboriginal Villages (臺灣番社風俗). Through the two (re)publication experiences, NCL has signed agreements with several publishers to reprint and republish Chinese rare books. Other value-added activities include physical and virtual exhibitions, e-learning syllabi and materials, and cultural-creative products.

The International Digitalization Project of Rare Books has brought together many Chinese rare books scattered worldwide into a systematic knowledge resource to serve as an academic reference for Chinese studies. It has enhanced NCL's academic reputation, and enabled NCL to become an internationally well-regarded knowledge hub. On the basis of the current Rare Books \& Special Collections information system, the NCL will construct a platform that facilitates digital humanities research. The platform will empower users to analyze and make discoveries in Chinese rare books, and enable researchers to employ digital humanities research methodology for exploring new research topics.

\section{DOMESTIC DIGITIZATION PROJECT OF MODERN CHINESE BOOKS}

In addition to Chinese rare books, the NCL owns many Chinese books published between 1911 and 1949 in Taiwan and mainland China. In view that digital curation is an appropriate solution for long-term preservation and reuse of those kinds of books, the NCL has been digitizing those books for many years. Many other Taiwanese libraries and government agencies hold this kind of books as well, but may not have the resources and budget to digitize them. As a mission of the NCL is to acquire, catalog and preserve national publications for government, research and general public use, the NCL deemed it mutually beneficial for the NCL, libraries and government agencies in Taiwan to collaboratively digitize Chinese books published in the twentieth century, especially during the period of 1911-1949, and thus started the Domestic Digitization Project of Modern Chinese Books in 2015.

The initial partners of this project include libraries and government agencies:

1. Government agencies: the NCL invited the Ministry of Culture and other culture-related agencies under the jurisdiction of Executive Yuan and local governments to participate. By May 2016, 85 government agencies were participating in the project.

2. Libraries: the NCL invited national libraries, academic libraries, and public libraries with large collections to participate. By May 2016, two national libraries (National Taiwan Library and National Library of Public Information), three academic libraries (National Taiwan University Library, National Taiwan Normal University Library, National ChengChi University Libraries) and one cultural affairs department of a local government (Peng-Hu County) have signed cooperative agreements.

The primary digitization targets are Chinese books, including:

1. Government publications: government publications without a copyright issue (for example, the copyright has expired or the government agencies are copyright holders).

2. Chinese books published during the period 1911-1949: Chinese books of cultural value. 
Table 1. Digitization status of the Domestic Digitization Project of Modern Chinese Books

\begin{tabular}{lrrrr}
\hline Institutions & Current (April, 2016) & \multicolumn{2}{r}{$\begin{array}{r}\text { Expected } \\
\text { (December, 2016) }\end{array}$} \\
\cline { 2 - 5 } & Titles & Images & Titles & Images \\
\hline National Central Library & 7,000 & 920,000 & 9,500 & $1,333,000$ \\
Collaboration partners & 1,988 & 464,163 & 3,200 & 764,163 \\
\hline Total & 8,988 & $1,384,163$ & 12,700 & $2,097,163$ \\
\hline
\end{tabular}

By April 2016, the project had completed the digitization of 8,988 titles, with $1,384,163$ images. It is anticipated that by the end of 2016, the project will have digitized 12,700 titles with 2,097,163 images. Table 3 provides more details. The digitized books cover 12 subjects, including general works, philosophy and religion, science and engineering, agriculture (forestry, fishing, animal husbandry), medicine and home and family management, economics and finance, education, social sciences, political science and law and military, history and geography, language and literature, and art.

As with the International Digitalization Project of Rare Books described earlier, this project follows the guidelines of the National Digital Archives Program for digitizing books; specifically, the full-color (24-bit) scanning process produces 300dpi TIFF format for longterm preservation, 200dpi JPG format for Internet download, and 72dpi GIF format for preview. In addition, PDF files are made available for e-books. The two- or three-iteration of quality control process includes image completeness check, page sequencing check, dust and specks removal, and contrast and lighting adjustment. The books are described using Dublin Core metadata.

The next step of this project is to make the digitized books accessible online. The information system for searching, retrieving and downloading the digitized books is under development, and is scheduled to be available in the autumn of 2016.

Although this project is just in its initial phase, it has already shown the value of preserving Chinese books published in the twentieth century. Inspired by HathiTrust (Wikipedia, 2016b), the NCL is considering expanding this project to major research institutions and libraries. A system that empowers partners to ingest their digitized books and allows users to access the digitized books permitted by law or by the copyright holders will be built. In this manner, valuable Chinese books (or more broadly, any kind of Chinese cultural records) can be preserved, disseminated and reused.

\section{CONCLUSION}

This article has described two digital curation projects conducted by the National Central Library, Taiwan. The first project aims at digitizing Chinese rare books through collaboration with international libraries, including the U.S. Library of Congress, the University of Washington, the University of California, Berkeley, the University of Toronto, and the Bibliothèque nationale de France. The second project aims at digitizing Taiwanese government publications and Chinese books published in Taiwan and mainland China during the period 1911-1949, with about 90 government agencies and libraries participating in the project. The two projects have digitized nearly 3,500 and 9,000 titles, respectively, with a 
total of three million digital images. In the future, the NCL will continue to developing collaborative relationships with more cultural institutions, globally and domestically.

Digitization is just one step of digital curation. The International Digitalization Project of Rare Books has developed an information system that allows users to search, browse and read the digitized rare books online. In addition, physical and virtual exhibitions that highlight the project achievement have been held, e-learning syllabi and materials have been created, and the NCL is undertaking the reprint and republication of several invaluable Chinese rare books in paper format and design cultural-creative products. The experience gained in carrying out the International Digitalization Project of Rare Books provided a good basis for the Domestic Digitization Project of Modern Chinese Books, which is in its inception phase.

Digital preservation is a key part of digital curation. Digital preservation concerns the use of managed activities to ensure longevity and long-term utility of digital resources. It comprises preservation planning and actions such as refreshing, migration, and emulation (Digital Preservation Coalition, 2016). The two projects described in this article has started to consider the issues of digital preservation, and plan to refer to the OAIS reference model (Consultative Committee for Space Data Systems, 2012) to address them.

\section{REFERENCES}

Consultative Committee for Space Data Systems. (2012). Reference model for an Open Archival Information System (OAIS). Retrieved from http://public.ccsds.org/publications/archive/650x0m2.pdf

Digital Curation Centre. (2008). What is digital curation? Retrieved from http://www.dcc.ac.uk/digital-curation/what-digital-curation

Digital Preservation Coalition. (2016). Digital preservation handbook. Retrieved from http://handbook.dpconline.org/.

Harvey, D. R. (2010). Digital curation: a how-to-do-it manual. NY: Neal-Schuman Publishers.

National Central Library. (2012). Visions: Collection digitization. Retrieved from http://enwww.ncl.edu.tw/informationlist_8.html

Taiwan e-Learning and Digital Archives Program. (n.d.) Preface. Retrieved from http://teldap.tw/en/index.html

Wikipedia. (2016a). Digital Curation. Retrieved from https://en.wikipedia.org/wiki/Digital_curation

Wikipedia. (2016b). HathiTrust. Retrieved from https://en.wikipedia.org/wiki/HathiTrust 